------ Raf. J. Sci., Vol. 23, No.1 pp 60-67, 2012------

\title{
Study the Effect of some Physical Parameters on the Diffusion Properties of Prepared Alginate-Chitosan Capsule
}

\author{
Noha M. Yahya \\ Department of Pharmaceutical Science \\ College of Pharmacy \\ University of Mosul
}

(Received 1/11/2010 ; Accepted 26/9/2011)

\begin{abstract}
Colloid hydrogel spherical core of alginate-chitosan capsules which is used to surround a bovine serum albumin were prepared using coacervation method. The effective physical parameters on porosity or permeability of chitosan-alginate polyions membrane were determined by the manipulation of solution conditions such as $\mathrm{pH}$, ionic strength, and polymer concentration of chitosan. Different $\mathrm{pH}(3.9,4.9,5.9)$ and different concentrations of chitosan $(0.1 \mathrm{~g}, 0.2 \mathrm{~g}, 0.3 \mathrm{~g})$ as well as with and without $\mathrm{NaCl}(0.0,0.1$, $0.2,0.3 \%$ ) were used to study the release of bovine serum albumin (BSA, molecular weight $=69,000)$ in vitro from the capsule prepared from alginate-chitosan blended polymer. The overall diffusion of BSA through the chitosan capsule membrane increased as the $\mathrm{pH}$ increased from 3.9 to 5.9. Also, an increase in the concentration of $\mathrm{NaCl}$ in the chitosan solution used in the preparation of capsule caused an increase in the diffusion of the protein. In contrast, an increase in the concentration of chitosan solution from $0.1 \mathrm{~g}$ to $0.3 \mathrm{~g}$ caused a decrease in diffusion of the proteins.
\end{abstract}

Keywords: chitosan, complex coacervation, drug delivery system, diffusion properties.
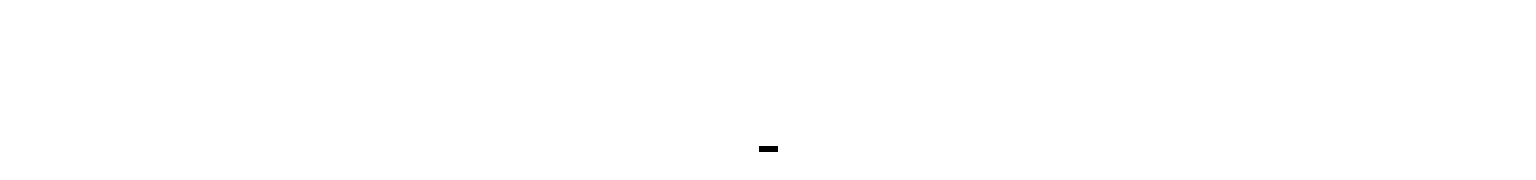

\section{lla}

لقد مت تحضير مستحضر جلاتيني غروي من ماة الالجينيت والجيتوسان والذي يستخم غلافأ لماة

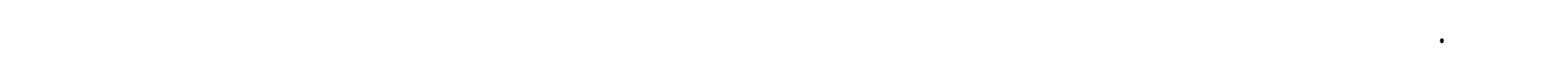
وتأثير الدالة الحلمضية 3.9 و 4.9 و 5.9 على قابلية الانتشار.

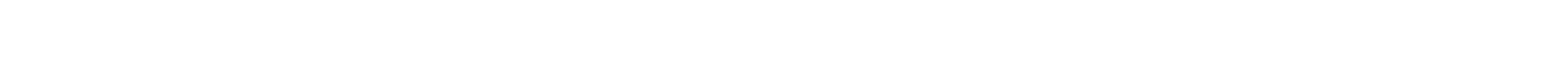
( 0.0 و0.1 و0.2 و0.3\%) على قبلية الانتشار. لوخظ النه عند ازياد قيمة الدالة الحلمضية وزيادة تركيز 


\section{كلوريد الصوديوم في محلول الجيتوسلن تزداد قابلية الانتشار وذك بزياةة تركيز الالبومين المقلس. وعل ؟

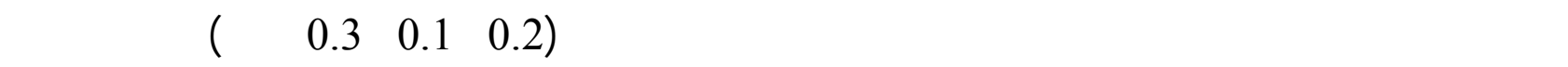 قابلية انتشار الالبومين.}

\section{INTRODUCTION}

Chitosan is a polysaccharide-based bipolymer, poly-( $1 \rightarrow 4)-2$-amino-2-deoxy- $\beta$-Dglucose, obtained by deacetylating of chitin which is the major constituent of exoskeleton of crustaceous such as crab and shrimp shells.

The process of deacetylation involves the removal of acetyl groups from the molecular chain of chitin leaving behind a compound of chitosan with a high degree of chemical reactive amino group. The degree of deacetylation DD is an important property in chitosan production as it affects the physicochemical properties, hence determines its appropriate applications, biodegradibility and immunological activity (Tolaimate, 2000). Chitosan can be applied in drug delivery system with different routes of administration as well in food industry, agriculture, biomedical, waste water treatment, membrane, and wall material of the capsule (Mattheus, 1997).

Methods to prepare capsule include; first complex coacervation, which is a process in which chitosan is used as a cationic polyelectrolyte to interact with an anionic polyelectrolyte such as alginate, carrageenan, or arabic gum to form the wall material (Murali et al., 2001). Second, adjustment of the solution $\mathrm{pH}$ to beyond the isoelectric point of chitosan which causes precipitation and aggregation, then forming the wall material (Lim, 1991). Third, in situ polymerization: in which opposite charged compounds, such as polyphosphate and chitosan, mixed in the solution. Polymerization occurs in the interfacial membrane and forms the wall material of the capsule (Beaumont, 1987). Hwang et al., (1986) proposed that the morphology of the chitosan plays a significant role in the structure of the capsule membrane. Thus, the morphology of the chitosan molecules can be changed to form a special network that results in the increase of the wall thickness (Hsieh et al., 2007). Slioyn and Rha (1989) reported that the release rate of the chitosancarboxymethylcelluulose capsule increased by increasing the concentration of sodium chloride or phosphate. The release rate increase due to addition of sodium chloride is greater than that due to addition of phosphate. However, the release rate of the capsule prepared from lower molecular weight chitosan is lower than that prepared from higher molecular weight of chitosan (George, 2006). The effect of chain flexibility of chitosan molecules on the preparation, physical properties, and release rate of the prepared capsule were investigated (Rong, 1997). The polyelectrolyte complex film of chitosan and alginate was used for sustained drug delivery of potent antimicrobial and antifungal drugs by transdermal drug delivery (Bhupendra et al., 2009). Moreover, the main mechanism for forming the membrane is the electrostatic interaction between positively charged amino groups on chitosan chain and the negatively charged groups on counter polyanions backbone. Hence, theoretically, it should be possible to control the porosity and permeation characters of a membrane by the physical and processing conditions contributed to the 
polymer chain conformation in solution (Hsieh et al., 2007). The objective of this study is to evaluate the diffusion properties of chitosan-alginate capsule prepared by complex coacervation method at different $\mathrm{pH}$, ionic strength and concentration of chitosan solution.

\section{MATERIALS AND METHODS}

\section{Materials and instruments}

Chitosan was purchased from Orient Company Malaysia. Sodium alginate was supplied by Sigma. Sodium chloride and phosphate buffer were obtained from APS Chemicals. Calcium acetate was obtained from AJAX Chemicals, Australia. BSA was obtained from Sigma company.

Fourier Transform Infrared Spectrophotometer (FT-IR) spectra of chitosan was recorded on the FT-IR spectrophotometer (Perkin-Elmer 1725X at University Putra Malaysia), using potassium bromide pellet technique. BSA diffusion was determined by UV- Visible Spectrophotometer (Carrywinn U.V. Varian at college of Pharmacy, Mosul University ).

\section{Determination of the degree of deacetylation of chitosan}

Chitosan and $\mathrm{KBr}$ at a ratio of $1: 100$ was mixed well, dried, and then made into a disc. The IR spectrum was measured by FT-IR spectrophotometer with a frequency range of 400-4000 $\mathrm{cm}^{-1}$ The following methods were proposed for determination the DD of chitosan depended on the base-line of the IR spectrum which are given via (1) Domszy and Roberts, 1985. (2) Sabinis and Block, 1997. (3) Baxter et. al,1992. (4) Rout, 2001 that considered in our calculation of DD value. Equation 1 is applied to determine the DD value.

$$
\mathrm{DD} \%=118.883-\left[40.1647 \times\left(\mathrm{A}_{1655} / \mathrm{A}_{3450}\right)\right]
$$

where $A_{1655}$ is the absorbance of the amide band at $1655 \mathrm{~cm}^{-1}$ and $A_{3450}$ is the absorbance of the $\mathrm{O}-\mathrm{H}$ band at $3450 \mathrm{~cm}^{-1}$. The factor 40.1647 denotes the value of the ratio of $\mathrm{A}_{1655} /$ $\mathrm{A}_{3450}$ for fully $\mathrm{N}$-acetylated chitosan. The number 118.883 was proposed to be related to the baseline (Rout, 2001). It was reported that the DD is one of the more important chemical character (Li et al., 1997), which could influence the performance of chitosan in many of its application. In addition, the DD determines the content of free amino groups in the polysaccharides, which can be employed to differentiate between chitin and chitosan (Baxter, 1992). Tolaimate in 2000 has reported that material becomes an intereasting in pharmaceutical application with a DD value of $75 \%$ or above due to its biocompatibility and low toxicity.

\section{Preparation of capsules using complex coacervation method}

The preparation of chitosan capsules was based on the method of Hwang et al., (1986). Chitosan $0.1 \mathrm{~g}$ was dissolved in $0.2 \mathrm{M}$ acetic acid $(5 \mathrm{ml})$, and $5 \mathrm{~m} M$ calcium acetate $(5 \mathrm{ml})$, then the $\mathrm{pH}$ adjusted at $3.9,4.9$, and/or 5.9 to obtain the optimum $\mathrm{pH}$. The core material, $0.3 \%$ bovine serum albumin, was mixed with $1.2 \%$ of sodium alginate 
containing $\mathrm{NaCl}$ salt. By using burette, the BSA alginate solution was dropped into the chitosan solution to form the capsule with no stirring (the volume of each dropwise about $0.1 \mathrm{ml})$. The droplet capsule was cured for $5 \mathrm{~min}$. at room temperature and then collected.

To study the effect of ionic strength of chitosan solution on the transmembrane diffusion, $\mathrm{NaCl}$ in different concentrations $(0.0,0.1,0.2,0.3 \%$ chitosan weight basis) were added to the chitosan solution and then adjusted at optimum $\mathrm{pH}$ that determines in previous step. Then the above experiments were repeated for the chitosan solutions of 0.2 and $0.3 \mathrm{~g}$.

\section{Diffusion of Protein}

About 50 capsules containing albumin were transferred to $50 \mathrm{ml}$ of potassium phosphate buffer solution $(\mathrm{pH}$ 7.4). The diffusion of protein from inside to outside the capsules was determined by measuring the absorbances of $5 \mathrm{ml}$ of release media at $280 \mathrm{~nm}$ (using UV- Visible Spectrophotometer ) during a set time interval of each 20 min.. Protein concentrations at a particular time were plotted against time. A plot of known concentrations of albumin against their absorbance were used to obtain a standard curve (Kim et al., 1999). Then, the standard curve was used to determine the unknown concentration of diffusive albumin outside the capsules.

\section{Degree of Deacetylation}

\section{RESULTS AND DICUSSION}

The process of deacetylation involves the removal of acetyl groups $\left(-\mathrm{COCH}_{3}\right)$ from the molecular chain of chitin, leaving behind a complete amino groups $\left(-\mathrm{NH}_{2}\right)$, and chitosan versatility depends mainly on the high degree chemical reactivity of amino group. Deacetylation may be achieved by chemical process (Sandford, 1987) or by fermentation using microorganism (Healy, 1994). The DD is simply calculated from equation 1 :

$$
\mathrm{DD} \%=118.883-[40.1647 \times(61.74 / 85.61)]=89.917
$$

The DD from FT-IR spectra of using chitosan, Fig.1, was found to be about $90 \%$ which is commonly used in pharmaceutical applications and it is in agreement with the previous study (Tolaimate, 2000 ). 


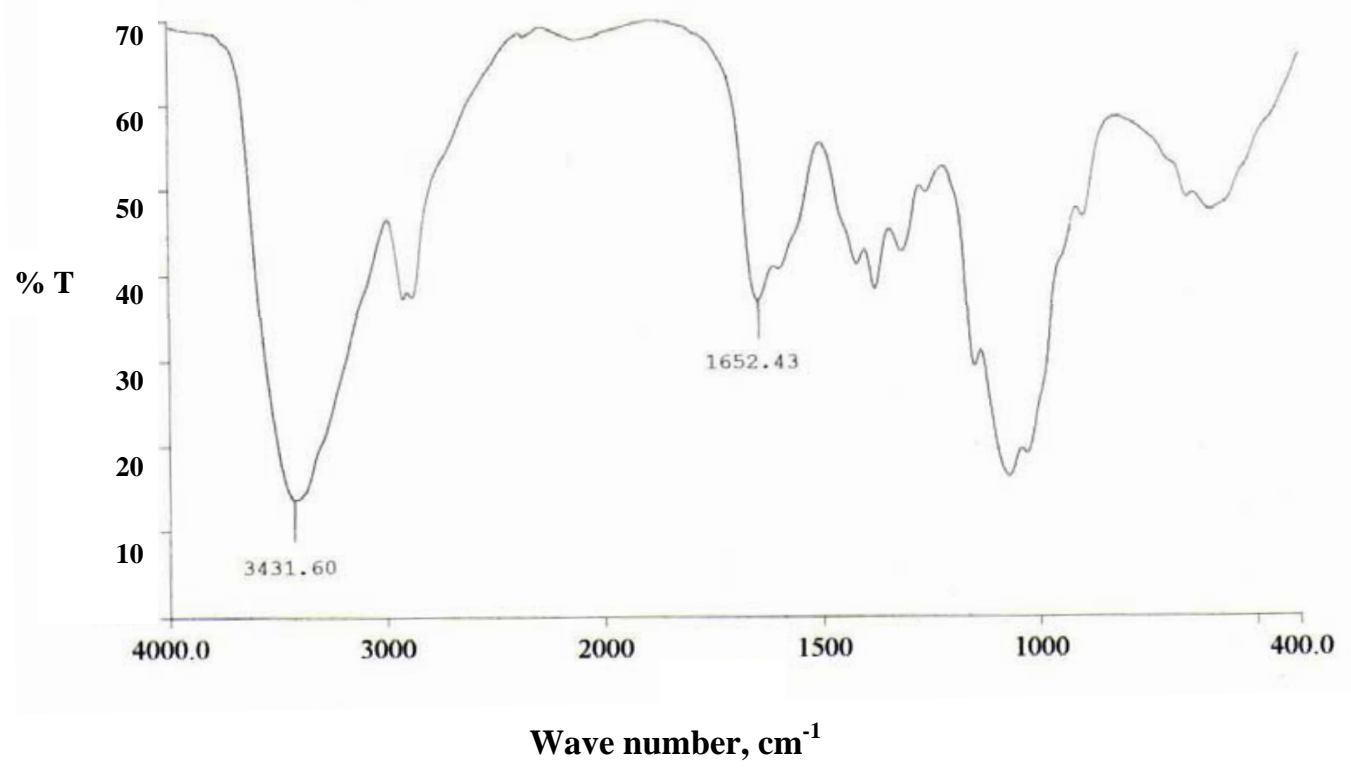

Fig. 1: FT-IR Spectra of chitosan (Transmmitance vs. Wave Number in $\mathrm{cm}^{-1}$ )

\section{In-vitro diffusion of Protein}

Different solution conditions including $\mathrm{pH}$, ionic strength and chitosan concentrations were used. The variation in the constitution leads to change in the frequency of the electrostatic interactions between chitosan and alginate, and then the nature of the structure of membrane network (Erkesh, 2008).

The diffusion rate of BSA through membrane from the inside to outside the capsules at different $\mathrm{pH}$ is shown in Fig. 2. An increase in $\mathrm{pH}$ of the chitosan solutions from 3.9, 4.9 and 5.9 will cause an increase in the diffusion rate from $48.76,52.85$ and to $111.55 \mu \mathrm{g} / \mathrm{ml}$. min, respectively. This may attributed to the intrinsic viscosities of chitosan in different $\mathrm{pH}$ solutions. A higher intrinsic viscosity indicates that molecule will be more extended in the solution (Li et al., 1992). The extended molecule will increase that chances to be involved in intermolecular entanglements. Thus, as $\mathrm{pH}$ increasing the counter ion interaction of chitosan-alginate decreased and that caused an increase in the diffusion rate of drug. Consequently, the relationship between $\mathrm{pH}$ and diffusion rate gives a good indication about the porosity of the membrane (Hsieh, 2007).

The effect of the ionic strength in term of different percent of $\mathrm{NaCl}$ on the transmembrane diffusion of protein in the capsule with time is shown in Fig. 3. The diffusion properties of capsules suggest inconsistent concentration at the beginning. After one hour, diffusion of BSA increased with time by increasing the $\mathrm{NaCl}$ concentration in chitosan solution. Capsules prepared from solutions containing $0.2 \% \mathrm{NaCl}$ have larger diffusion rate than those containing $0.3 \% \mathrm{NaCl}$. This may be attributed to the counter-ion effect which depresses the third electroviscous effect and render the chitosan molecules to be more flexible with randomly coiled shape (Bhupendra et al., 2009).

The effect of the chitosan concentration on the diffusion of BSA is shown in Fig. 4. The diffusion rate decrease with an increase in chitosan concentrations but increased for 
$0.3 \mathrm{~g}$ of chitosan concentration. The diffusion of BSA in the capsules prepared with $0.1 \mathrm{~g}$ chitosan was higher than the capsule prepared with $0.2 \mathrm{~g}$ chitosan. However the diffusion rate is almost same after 3 hours. The diffusion of BSA in the capsules prepared with $0.3 \mathrm{~g}$ chitosan showed the inconsistent result. This result may due to the increase of algination created in the small concentarion $(0.1 \mathrm{~g})$ of chitosan compared to the higher concentration of chitosan $(0.2 \mathrm{~g}$ and $0.3 \mathrm{~g})$.

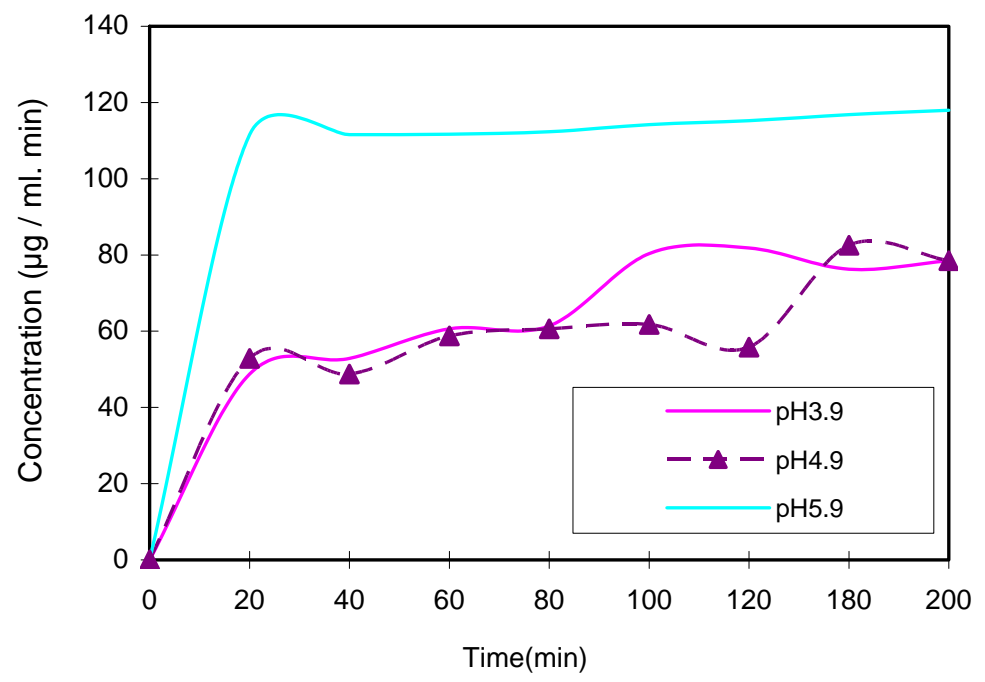

Fig. 2: Diffusion of BSA from the capsules prepared from chitosan solution at $\mathrm{pH} 3.9,4.9,5.9$ at room temperature using $0.1 \mathrm{~g}$ of chitosan.

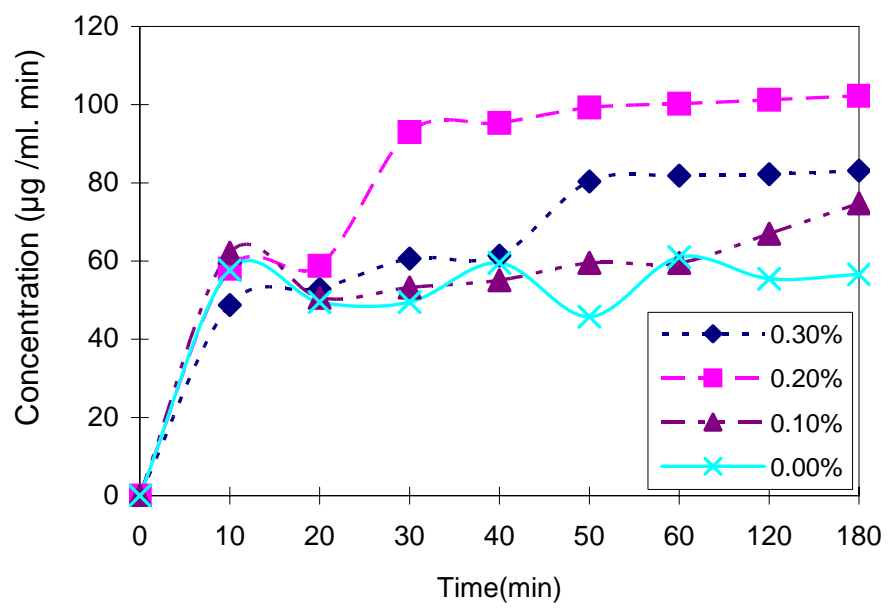

Fig. 3: Effect of $\mathrm{NaCl}$ percent on BSA diffusion at room temperature from capsules prepared of $0.1 \mathrm{~g}$ of chitosan solution at $\mathrm{pH}$ 5.9. 


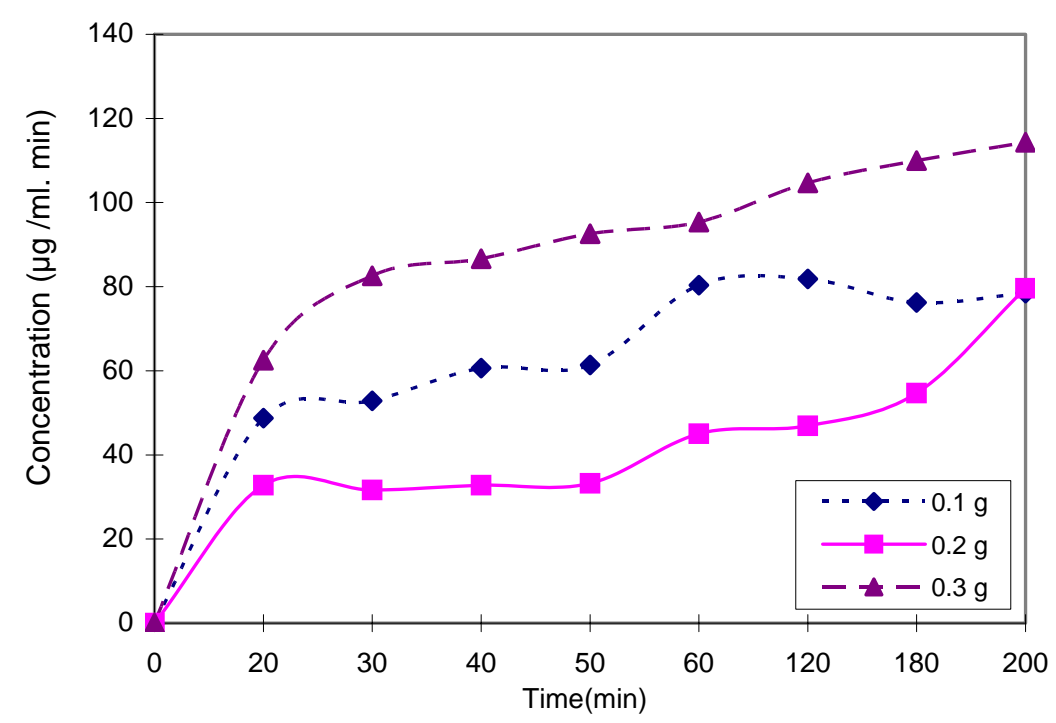

Fig. 4: Effect of chitosan concentrations on diffusion of BSA at room temperature and $\mathrm{pH} 5.9$.

\section{CONCLUSION}

In this study the DD of chitosan was $90 \%$. So that, chitosan is an interested material in pharmaceutical application due to its biocompatibility and low toxicity. The results showed that the physical parameters have an effects on the porosity of chitosan-counter polyion membrane which can be controlled by $\mathrm{pH}$ of chitosan solution (at 5.9) and the percent of $\mathrm{NaCl}$ concentration (fixed at the $0.2 \% \mathrm{NaCl}$ ). Chitosan of $0.3 \mathrm{~g}$ has a significance effect on drug diffusion. The use of such system makes it possible to develop systems with required rate of drug delivery to the body in accordance with the pre set time program.

\section{REFERENCES}

Baxter, A.; Dillon, M.; Taylor, K.D.A; Roberts G.A.F. (1992). Improved method for I.R. determination of the degree of $\mathrm{N}$-acetylation of chitosan. Int. J. Biol. Macromol., 14,166-169.

Beanmont, M. D.; Knorr, D. (1987). Encapsulated active material system, Biotechnol. Lett., 9, 377.

Bhupendra, G. P.; Krutika, K. S. (2009). Poly electrolyte complex of chitosan alginate for local drug delivery. Inter. J. Chem. Tech. Res., 1, 643-648.

Domszy, J. G.; Roberts, G.A.F. (1985). Evaluation of IR techniques for analyzing chitosan. Macromol Chem., 186, 1671-1677.

Erkesh, O. B. (2008). Modified microparticles of calcium alginate gel for controlled release of anesthetics. Mater. Res. Soc., Symp., 1060 .

George, M.; Abraham, T.E. (2006). Polyionic hydrocolloids for intestinal delivery of protein drugs: alginate and chitosan. J. Control. Rel. 114, 1-14. 
Healy, M. G. (1994). Microbial aspects of chitosan employment in hypocalone extraction of chitin from prawn waste. J. Acta Toxicol. 17, 287-302.

Hsieh, W.C.; Chang, C.P.; Lin, S. M. (2007). Morphology and characterization of 3D micro-porous structured chitosan scaffolds for tissue engineering. Colloids and Surfaces B: Biointerfaces, 57, 250-255.

Hwang, C.; Rha, C. K.; Sinskey, A. J. (1986). "Effect of Molecular Weight, Chain Flexibility and Chemical Modification on the Properties of Chitosan Ultrafiltration Membranes in Chitin in Nature and Technology", Eds., plenum, New York, 389 p.

Kim, H.J.; Lee, H.C.; Oh J.S.; Shin, B.A.; Park R.D.; Yang, K.S.; Cho, C.S.(1999). Polyelectrolyte complex composed of chitosan and sodium alginate for wound dressing application. J. Biomaterial Sci. Polym. 10, 543-556.

Lim, W. C. (1991). Rheological properties and chain flexibility of chitosan with different degrees of deacetylation, Master thesis, Department of Marine Food Science, National Taiwan Ocean University.

Li, J., Revol, J.F.; Marchessault, R.H. (1997). Effect of degree of deacetylation of chitin on the properties of chitin crystallites. J. Appl. Polym. Sci., 65(2), 373-380.

Li, Q.; Dunn, E.T.; Grandmaison E.W.; Goosen, M. F.A.(1992). Application and properties of chitosan. J. Bioact. Compat. Polym.,7, 370-397.

Mattheus, F. A. (1997). "Applications of Chitin and Chitosan". Eds., Technomic publishing company, CH- 4055 Basel, Switzerland.

Murali, G.V.; Himasankar, K.; Cheruvu, P.S.; Ramana, K.V. (2001). Controlled release of diclofenac sodium by gum karayachitosan complex coacervation:in vitro evaluation. Indian J. Pharma. Sci. 63, 408-412.

Rong, H. C.; Min, L.T. (1997). Effect of preparation method and characteristics of chitosan on the mechanical and release properties of the prepared capsule. J. Appl. Polym. Sci., 66, 161-169.

Rout, S. K. (2001). Ph. D. Thesis on physicochemical functional and spectroscopic analysis of crawfish chitin and chitosan affected by process modification. dissertation, Louisiana state university, Baton, Rouge, La, USA.

Sabnis, S.; Block, L.H.. (1997). Improved infrared spectroscopic method for analysis of degree of N-acetylation of chitosan. Polym Bull., 39, 67-71.

Sandford, P.A.; Hutchings, G.P. (1987). "A natural antionic biopolymer commercial application. Ed. Elsevier Science Publisher, 363-374.

Slioyn, T.; Rha, C.K. (1989). In chitin and chitosan sources, chemistry, Biochemical, physical properties and application. Eds., Elsevier Applied Sci., publishers, London, 627.

Tolaimate, A.; Desbrieres, J.; Rhazi, M.; Alagui, A.; Vicendon, M.; Vottero, P. (2000). On the influence of deacetylation process on the physicochemical characteristics of chitosan from squid chitin. Polymer J. 41, 2463-2469. 